\title{
PRÁTICAS ARTÍSTICAS PARA DIVULGAR NEUROCIÊNCIA: RELATO DO EVENTO “CONHECENDO O CÉREBRO”
}

\section{ARTISTIC PRACTICES FOR DISSEMINATING NEUROSCIENCE: REPORT OF"KNOWING THE BRAIN" EVENT}

DOI: http://dx.doi.org/10.5965/1984317813032017224

Matheus Augusto Silva, Ana Lúcia De Grandi, Roberta Ekuni - Universidade Estadual do Norte do Paraná Bruna Jamila de Castro - Universidade Estadual de Londrina

\begin{abstract}
RESUMO
O presente relato de experiência visa apresentar a proposta do evento "Conhecendo o Cérebro" que utilizou práticas artísticas na divulgação científica da Neurociência. Diversas formas de expressões artísticas, como desenho, pintura e escultura, foram incluídas nos estandes, dentre eles: neurobalão, confecção de óculos 3D, cantinho da leitura, neurônios de massinha, atividades de pintura em estandes de sono e drogas e desenhos na lousa digital. Os resultados apontam que as práticas artísticas utilizadas podem ser potentes ferramentas pedagógicas de divulgação da Neurociência. A valorização da criatividade e da inovação através de ações diferenciadas despertaram o interesse e curiosidade das pessoas não pertencentes à comunidade científica, promovendo uma participação ativa do visitante.
\end{abstract}

Palavras-chave: Divulgação científica. Neurociência. Educação. Práticas Artísticas.

\begin{abstract}
The present experience report aims to present the proposal of the event "Knowing the Brain" that used artistic practices in the scientific dissemination of Neuroscience. Various manners of artistic expressions, such as drawing, painting and sculpture, were included in the event, among them: neuroballoon, 3D glasses making, reading corner, neurons of clay, painting activities in stands that explains sleep, drugs and drawings on the digital board. The results show that the artistic practices used can be powerful pedagogical tools for the dissemination of Neuroscience. The valorization of creativity and innovation through differentiated actions aroused the interest and curiosity of people not belonging to the scientific community, promoting an active participation of the visitor.
\end{abstract}

Keywords: Scientific dissemination. Neuroscience. Education. Artistic Practices. 


\section{INTRODUÇÃO}

A divulgação científica para fins educacionais visa oportunizar que o conhecimento científico e tecnológico esteja disponível a todos, além de almejar estimular a curiosidade científica do cidadão. Sua função principal é a de traduzir as informações complexas do âmbito da pesquisa científica para uma forma de linguagem mais acessível ao público leigo (ALBAGLI, 1996), o que envolve a busca por estratégias e ferramentas pedagógicas que permitam uma educação científica de qualidade, disponível e acessível a todos, inclusive as pessoas de diferentes faixas geracionais e em situação de deficiência física ou intelectual (CAMPOS, 2015).

Frente essa percepção, da necessidade de estratégias/ferramentas que permitam uma transposição didática adequada no campo da divulgação científica, e considerando que as diferentes perspectivas no campo da Educação Científica apontam para "uma educação que possibilite o desenvolvimento de habilidades, valores e atitudes dos cidadãos, em que estes sejam os protagonistas no processo educativo" (NASCIMENTO JÚNIOR; SOUZA, 2009, p.72), desenvolvemos por dois anos consecutivos uma proposta de evento de extensão universitária que buscou na articulação entre artes e educação inspiração para transcender a forma expositiva tradicional de se apresentar os conhecimentos científicos para a comunidade não científica.

No Brasil várias pesquisas têm articulando práticas artísticas ${ }^{1}$ e o ensino de ciências (TEIXEIRA et al., 2001; TEIXEIRA; NASCIMENTO JÚNIOR, 2002; HOLDELFER et al., 2002; LIBERA et al., 2003; SOUZA; ARANTES; NASCIMENTO JUNIOR, 2006; COSTA; SOUZA; NASCIMENTO JÚNIOR, 2005; NASCIMENTO JÚNIOR; SOUZA, 2009; RIBEIRO; FERNANDES, 2010; para citar algumas), todas tem apontado ocupações manuais, aulas interativas, vivências corporais como práticas/experiências artísticas que ampliam a capacidade cognitiva e desenvolvessem uma atitude proativa nos aprendizes. Foi com base nestas pesquisas que desenvolvemos nossa proposta.

\footnotetext{
${ }^{1}$ Denominamos como "práticas artísticas", de um modo um tanto reducionista, técnicas/processos de criação oriundos do campo de conhecimento das Artes, como o desenho, a pintura e a escultura, tal como fazem Rosenthal e Gonçalves (2012), Ribeiro e Fernandes (2010), Nascimento Júnior e Souza, (2009), e as utilizamos somente como ferramentas lúdicas e pedagógica para atingir o objetivo específico de divulgar a Neurociência, nos distanciamos, desta forma, da discussão que trata a arte como linguagem expressiva e forma de conhecimento complexo.
} 
O evento em questão, denominado "Conhecendo o cérebro", foi organizado pelo "Grupo de Estudos em Neurociência" da Universidade Estadual do Norte do Paraná (EKUNI et al., 2014, 2016). O evento fez parte da Semana Nacional de Ciência e Tecnologia (SNCT) por dois anos consecutivos, uma campanha promovida pelo Ministério da Ciência, Tecnologia, Inovações e Comunicações (MCTIC), por meio do Departamento de Difusão e Popularização da Ciência e Tecnologia (DEPDI/SECIS) ${ }^{2}$. Seu objetivo foi divulgar conhecimentos neurocientíficos para a comunidade do norte do Paraná de forma gratuita.

A motivação para desenvolvimento de um evento com esta temática deve-se ao fato da Neurociência ser uma área em expansão. Esse fato foi demonstrado por uma pesquisa realizada no Reino Unido, que fez um levantamento das publicações com temas de neurociência e mostrou que elas dobraram nos últimos dez anos avaliados (O'CONNOR; REES; JOFEE, 2012). Somado à esse fato, há uma alta disseminação de neuromitos informações equivocadas acerca do funcionamento do cérebro (PASQUINELLI, 2012) principalmente no âmbito da mídia e no campo da educação (EKUNI; POMPEIA, 2016; ZEGGIO et al., 2015). Posto que as evidências científicas que desmitificam os neuromitos geralmente são publicadas em periódicos científicos, nos quais o público leigo não tem acesso em larga escala (HOWARD-JONES, 2014), justifica-se a empreitada em trazer os conhecimentos referentes à neurociência ao alcance de todos ${ }^{3}$.

Buscamos oportunizar com o evento "Conhecendo o cérebro" um espaço instigante onde os participantes se sentissem estimulados a conhecer mais sobre seu cérebro, sua neuroanatomia, além do entendimento de como os sentidos são processados no cérebro, a importância da atividade física e do sono para a saúde do indivíduo, bem como oferecer conhecimentos relacionados à prevenção do uso de drogas, apontando os efeitos destas no organismo, tudo isso realizado por meio práticas artísticas como desenhos, pinturas e esculturas.

\footnotetext{
${ }^{2}$ A Semana Nacional de Ciência e Tecnologia (SNCT) tem como objetivo divulgar a ciência por todo o Brasil, mobilizando a população em torno de temas e atividades de ciência e tecnologia, valorizando atividades que demonstram a importância destas para a vida de cada um e para o desenvolvimento do País. Desse modo, instituições de todo o Brasil podem se cadastrar e realizar um evento de acordo com a temática proposta pelo MCTIC a cada ano.

3 No Brasil, já há iniciativas que visam desmitificar neuromitos nas redes sociais (https://www.facebook.com/cacadoresdeneuromitos) e por livros de divulgação neurocientífica, como o livro "Caçadores de Neuromitos: o que você sabe sobre seu cérebro é verdade?" (EKUNI; ZEGGIO; BUENO, 2015). Internacionalmente destacam-se iniciativas como: http://blogs.discovermagazine.com/neuroskeptic/\#.WZ2qH4grK00 e https://www.psychologytoday.com/blog/brain-myths
} 
Concordamos com Eisner (2002) que as Artes, embora comumente marginalizadas no âmbito educativo, são ferramentas importantes para desenvolver aspectos complexos e sutis da mente. No seu livro "The arts and the creation of mind", o autor destaca que ao se articular arte e educação refina-se os sentidos, amplia-se a imaginação, além de potencializar a cognição, desenvolver a autoexpressão criadora; a solução de problemas; entre outros. Por tais razões, e tendo em vista que um educador sem formação em Artes pode utilizar técnicas artísticas para ensinar um conteúdo, utilizando-a como ferramenta pedagógica, como argumenta Ramaldes (2017), apresentamos neste escrito nossa experiência com o evento "Conhecendo o cérebro", que buscou aliar práticas artísticas na divulgação da neurociência.

\section{MATERIAIS E MÉTODOS}

\subsection{Sobre o Evento "Conhecendo o Cérebro"}

As edições do evento ocorreram no mês de outubro de 2014 e 2015. Organizado pelo Grupo de Estudos em Neurociência da UENP, o mesmo foi realizado na Universidade Estadual do Norte do Paraná (UENP), Campus Luiz Meneghel, no município de Bandeirantes, Estado do Paraná. As atividades foram gratuitas e sua divulgação foi realizada por meio das redes sociais, convite às escolas e cartazes espalhados por diversos espaços públicos da comunidade.

Em 2014 foram onze estandes, dos quais cinco práticas artísticas, com expressões diversas: visuais, auditivas, corporais, literárias, entre outras. Já no ano de 2015 foram quinze estandes, sendo que nove envolviam práticas artísticas. A estética adotada para o evento foi de uma exposição, um ambiente rico em cores, interatividade, experimentos, painéis explicativos, grafismo etc., tudo o que proporcionasse um efeito visual atrativo e instigante. Todavia, os visitantes não se restringiam a apreciar os estandes, eles eram convidados à experimentação, com atividades que permitiam a interação com objetos, fenômenos, equipamentos e outros dispositivos motivadores, despertando curiosidades e, consequentemente, possibilitando aprendizagens específicas no campo da neurociência, contribuindo para a cultura científica do público. 
Para o funcionamento dos estandes, contou-se com a colaboração de monitores voluntários (alunos e professores dos cursos de graduação em Ciências Biológicas, Enfermagem e Sistemas de Informação). Cabe destacar que estes foram devidamente preparados anteriormente para as atividades, uma vez que, como divulgadores de ciência, deviam dominar não apenas o conhecimento específico, mas também dominar as diversas formas de comunicar e as ferramentas necessárias para a execução da ação.

\subsection{Descrição das Atividades dos Estandes}

Para fins de replicabilidade dos estandes, as técnicas de arte utilizadas estão descritas a seguir:

a) Neurobalão: escultura de neurônio, feita com bexigas de diferentes formas (bexigas canudos e bexigas tamanho zero), inspirada na atividade do Museu Itinerante de Neurociências (MUSEU, 2014). Devido ao sucesso desse estande em 2014, no lugar de dois monitores, em 2015 houve o auxílio de três a quatro monitores na execução da atividade. Para essa atividade, os monitores deixavam as bexigas previamente cheias e, conforme desenvolviam a atividade com os visitantes, explicavam as partes dos neurônios análogas à escultura das bexigas. Vale ressaltar que para crianças muito pequenas ou que diziam ter medo de manipular as bexigas, os monitores faziam a escultura de bexiga e no final entregavam para a criança. Posteriormente, para que mais pessoas pudessem visualizar como montar um neurobalão, foi publicado um vídeo explicativo no YouTube ${ }^{4}$.

b) Pinte o cérebro de gesso: atividade que envolve pintura de moldes de gesso em forma de cérebro, utilizando tintas à base de água e pincéis comuns. O objetivo foi estimular a coordenação e o tato para diferentes texturas e ensinar sobre os lobos cerebrais direito e esquerdo.

\footnotetext{
$\overline{{ }^{4} \text { Disponivel em: https://www.youtube.com/watch?v=3Vi-CPPzL2E\&t=4s }}$
} 
c) Pinte o cérebro de papel: atividade voltada para a pintura de desenhos com as estruturas encefálicas e subsequente explicação sobre sulcos, giros e lobos que dividem o cérebro. Posteriormente, os participantes preenchem as lacunas do desenho com o nome das divisões dos lobos cerebrais.

d) Estande da visão: confecção de óculos 3D a partir de folha de sulfite mais grossa, celofane azul e transparência pintada de tinta vermelha que os participantes utilizavam para assistir a um filme na sessão de cinema $3 \mathrm{D}^{5}$. O objetivo dessa atividade foi explicar como funciona a visão binocular, como enxergamos em $3 \mathrm{D}$ e enfatizar que o cérebro é o órgão responsável por processar essas informações visuais.

e) Cantinho da leitura: cantinho destinado à leitura de livros de divulgação neurocientífica para crianças com o livro "As dúvidas de Stem, uma pequena célula multipotente" e para o público jovem o livro "Caçadores de neuromitos: o que você sabe sobre seu cérebro é verdade?”, , esse último disponível apenas em 2015.

f) Neurônios de massinha: confecção de modelos de neurônios feitos de massa de modelar atóxica à base de amido. Devido ao fato da massinha comprada para o evento ser muito mole e grudar nos dedos, foi utilizada uma folha de papel para que os visitantes colocassem a massa em cima de modo a facilitar o manuseio. Enquanto o monitor ensinava a moldar os formatos, ele também explicava as partes e funcionalidades da célula nervosa de maneira divertida. Essa atividade estimulou a coordenação motora e criatividade na confecção do modelo.

g) Atividade de pintura e palavras-cruzadas no estande do sono: as atividades foram impressas em papel sulfite e distribuídas aos participantes após breve explicação sobre o funcionamento do sono. Em cada folha havia um desenho para colorir e uma atividade de palavras-cruzadas com palavras-chave vistas no estande.

h) Atividade de pintura no estande sobre drogas: as atividades foram impressas em papel A4 e após explicação sobre os efeitos das drogas no cérebro, as monitoras solicitavam

\footnotetext{
${ }^{5}$ Para descrição detalhada vide: EKUNI, R.; SOUZA, B. M. N.; WATANABE, A. K.; SANTOS, C. H. C.; MACHADO, G. A.; SOUZAJUNIOR, E. J.; CALVO, J. V. C.; GAIOTTE, L. B.; SILVA, M. A.; EBARA, M. M.; VIEIRA, M. N. F.; CESARIO, R. C. Evento 'Conhecendo o cérebro': divulgando e despertando interesse na neurociência. Revista Ciência em Extensão, v.12, n.2, p.125-140, 2016.

${ }^{6}$ Silva, Brockington e Queiroz (2003).

${ }^{7}$ Ekuni, Zeggio e Bueno (2015).
} 
aos participantes que pintassem as regiões do cérebro que eram afetadas pelos diferentes tipos de drogas. Foi apresentada a divisão das drogas em três classes (drogas depressoras, estimulantes e perturbadoras) e os efeitos cerebrais de cada classe. Também foi oportunizada aos visitantes a utilização dos óculos simuladores de embriaguez ( $3 \mathrm{~B}$ scientific $($ ) com o objetivo de entender, de maneira sóbria, os efeitos do álcool no organismo. Nessa atividade, os visitantes deveriam andar em linha reta, desviar de três balões (obstáculos) e tentar acertar um papel no cesto de lixo arremessando-o a uma distância de cerca de 2 metros.

i) Aprendizado e Lousa Digital: neste estande o visitante era convidado a representar um neurônio em uma lousa digital por meio de desenhos, com base em um modelo disponibilizado. A tecnologia permitia uma interatividade semelhante à que se tem com a tela de um Smartphone. Ao tocar a tela com o dedo, ou com uma caneta própria para essa finalidade, os sujeitos podiam caracterizar as estruturas de um neurônio utilizando vários recursos: canetas que permitiam traços de diversas espessuras e cores; caneta inteligente, que corrigia automaticamente traços e formas geométricas; ferramenta de colorir; ferramenta de autoformas; setas etc. A atividade visava, além de um momento agradável e prazeroso de se aprender neurociência, um ambiente para a expressão artística e criativa do visitante.

\section{RESULTADOS E DISCUSSÃO}

Analisaremos, Os resultados são baseados na percepção dos monitores/expositores e dos organizadores do evento, tendo como base as práticas artísticas como ferramenta para divulgar Neurociência. Com base no livro de visitas, mais de 1.100 pessoas visitaram o evento em seus dois anos de execução, sendo que no primeiro ano foram cerca de 300 pessoas e no segundo cerca de 800 pessoas.

Com relação à atividade do neurobalão, temos que ter em mente o conceito de criatividade, ou seja, como atributo humano ela é um ato, um conceito, uma estratégia (EÇA, 2010), um domínio cognitivo interligado à solução de problemas (SELBY; SHAW; HOUTZ, 2005). Os participantes deveriam usar a criatividade para esculpir um neurônio com balões. Isso pode ser visto pelo fato de o modelo original, proposto pelo Museu Itinerante de Neurociências (MUSEU, 2014), ter sido modificado pelo nosso evento em 2014 e remodelado 
em 2015 (Figura1) ${ }^{8}$. No ano anterior era necessária apenas uma bexiga canudo. Os dendritos eram representados por duas bexigas tamanho zero. Em 2015, as bexigas canudo foram cortadas ao meio, as duas metades foram cheias e enroladas em volta do que era a representação do corpo-celular do neurônio-balão. Ou seja, com a criatividade pôde-se fazer modelos diferentes de neurobalão: I) modelo original do neurobalão proposto pelo Museu Itinerante de Neurociências; II) Modelo do neurobalão do evento de 2014; III) Modelo do um neurobalão do evento de 2015; IV) Variações de neurobalãogrande, com duas bexigas canudos (uma para representar o corpocelular e outra para representar o axônio) e bexigas tamanho 7 no centro do corpo celular que pode ser visto na letra " $C$ " da Figura 1.

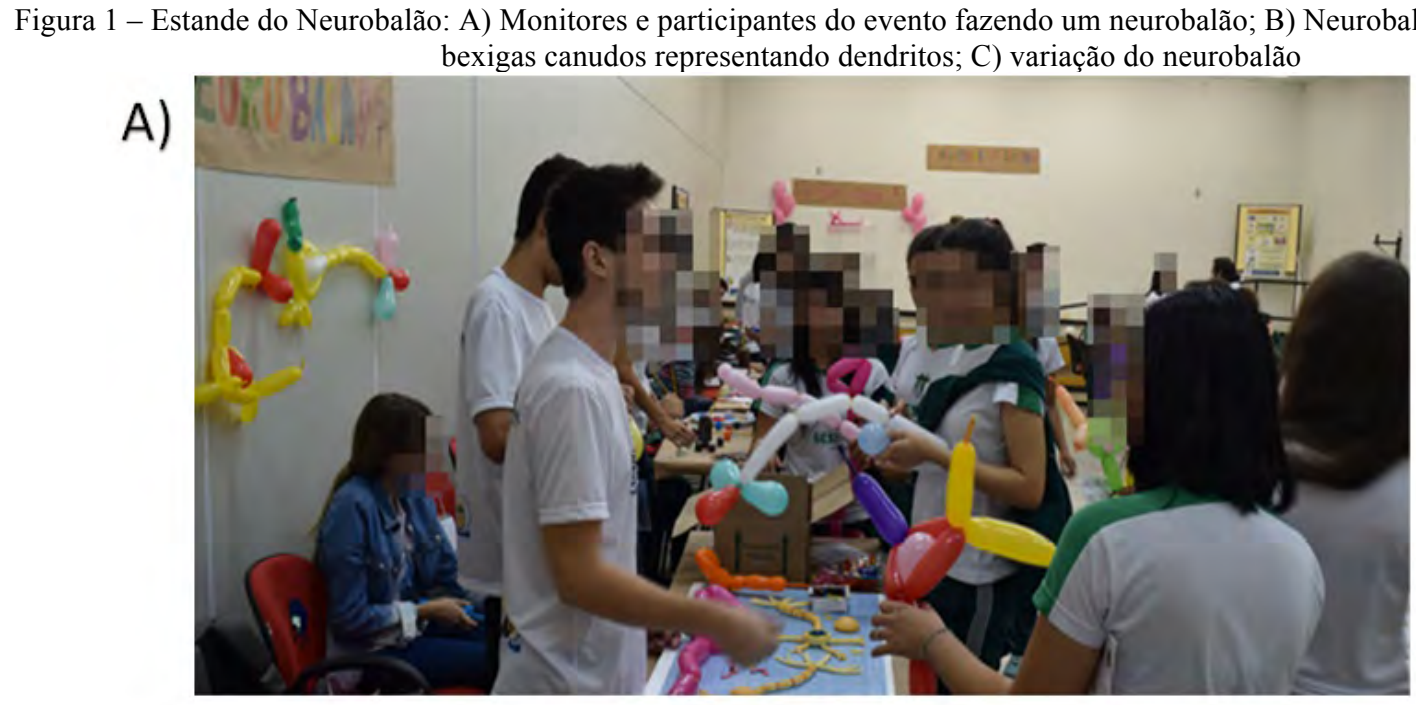

B)

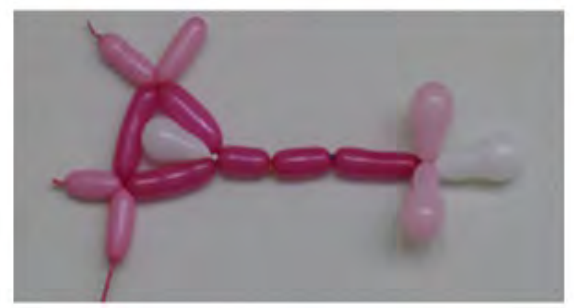

C)

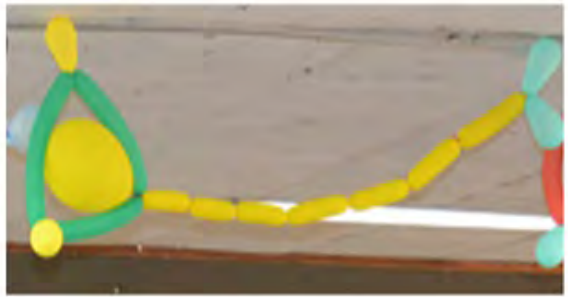

Fonte: Fotografia por Bruno Miguel Nogueira de Souza

\footnotetext{
${ }^{8}$ Para comparação, ver Figura 10 de EKUNI et al.(2016).
} 
Levando em consideração que há fatores individuais que contribuem para a expressão criativa, tais como sensibilidade a problemas, abertura a emoções e sentimentos, independência de pensamento, curiosidade, autonomia e persistência (SELBY; SHAW; HOUTZ, 2005), foi indispensável o ambiente do estande, que propiciou liberdade de escolha e de ação, com reconhecimento e estimulação do potencial para criar, como recomendam Alencar e Fleith (2003).

No estande de pintar o cérebro de gesso nos baseamos em Sholl-Franco e Veque (2013), que propõem que atividades de pinturas podem ser utilizadas para ensinar neurociência. Inicialmente os participantes recebiam um modelo de cérebro em miniatura, feito de gesso, no qual eles poderiam colorir com tinta guache. O monitor fornecia a seguinte instrução: "Vocês podem pintar um hemisfério de cada cor, ou um lobo cerebral de cada cor, ou podem usar a criar". Podemos perceber muitos cérebros elaborados com total liberdade de expressão pelas crianças, sem um modelo pronto. A Figura 2 apresenta as diferentes pinturas feitas pelos participantes do estande, levando em conta a imaginação e a mistura de cores e formas utilizadas por eles, trazendo vários efeitos visuais distintos para cada modelo de cérebro. Ao esculpir, desenhar ou pintar a anatomia corpórea é possível recriar mentalmente as estruturas observadas e refletir conceitos abstratos responsáveis pelo desenvolvimento cognitivo, contribuindo assim para a assimilação do conteúdo (Silva; Guimarãe, 2004). Alguns modelos podem ser vistos na imagem "B" e uma pintura criativa na imagem "C" da Figura 2, representando as conexões cerebrais. cérebros de gesso; B) Diversos modelos de cérebro de gesso com diferentes cores, formas e padrões de pintura; C) Variação de pintura de cérebro de gesso 


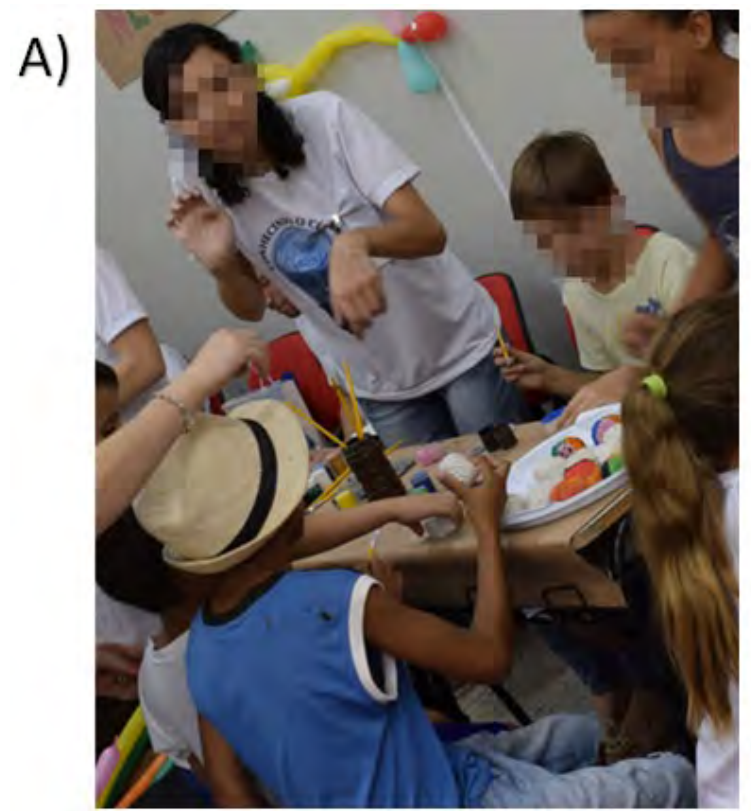

B)

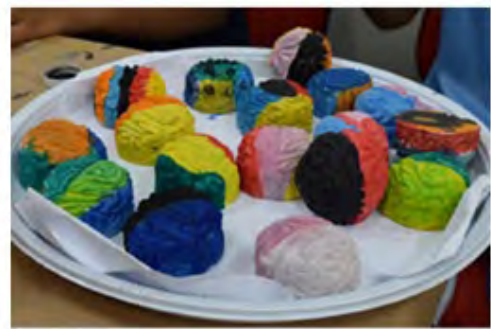

C)

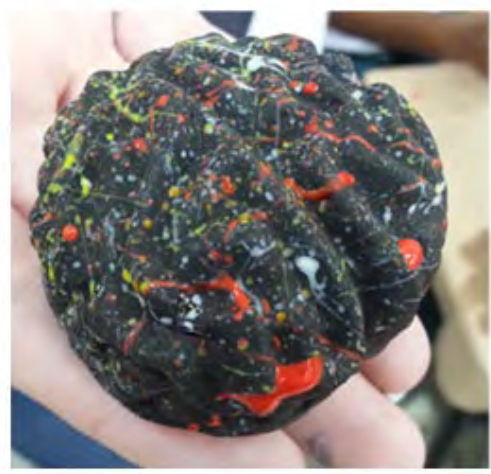

Fonte: Fotografia por Bruno Miguel Nogueira de Souza

Com relação à confecção dos óculos $3 \mathrm{D}$, os visitantes deveriam cortar e colar as lentes de modo a montar seus próprios óculos para assistir à animação 3D apresentada em um telão (Figura 3). De acordo com Seabra e Santos (2005), a utilização de recursos 3D ou de realidade virtual ajudam no desenvolvimento da cognição espacial, onde estes podem compreender objetos espaciais a partir de suas vistas principais, especificar vistas particulares e, adicionalmente, abstrair uma variedade de formas e raciocínio.

Figura 3 - Estande da visão e confecção do óculos 3D: A) Visitantes assistindo sessão de animação 3D em telão utilizando os óculos confeccionados no estande; B) Monitores e participantes do evento confeccionando óculos 3D 


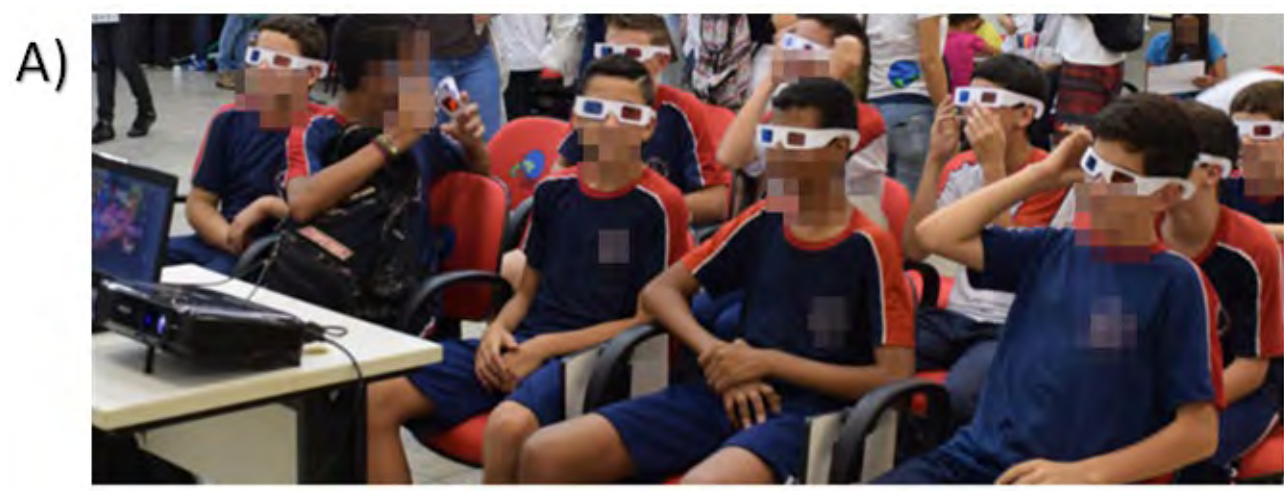

B)

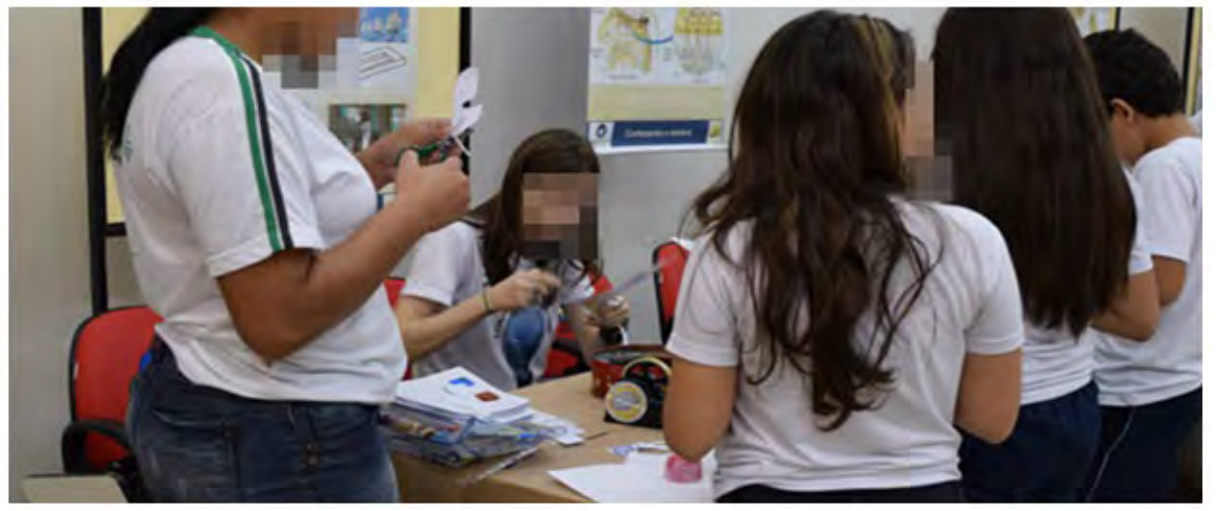

Fonte: Fotografia por Bruno Miguel Nogueira de Souza

No cantinho da leitura, os participantes puderam conhecer dois livros de divulgação neurocientífica (Figura 4). No caso do livro infantil "As dúvidas de Stem, uma pequena célula multipotente", os mesmos conseguiam lê-lo integralmente. Já o livro "Caçadores de Neuromitos: o que você sabe sobre seu cérebro é verdade?" era folheado e as pessoas liam apenas alguns trechos devido à extensão do mesmo. Esse foi o estande menos visitado em ambos os anos de execução do evento. O Retratos da Leitura no Brasil (2016) estima que apenas $56 \%$ da população brasileira é considerada "leitora", ou seja, aqueles que leram pelo menos um livro (inteiro ou em partes) nos últimos três meses. Isso pode ser uma causa para o pouco interesse dos visitantes a participarem desse estande, um panorama que apenas reforça a necessidade desse tipo de atividade nos diversos espaços educativos.

Segundo Girardello (2011), pesquisas revelam que os métodos de descoberta através da ficção criativa, como literatura, não são menos efetivos, em questão de aprendizagem, que procedimentos mais dedutivos ou científicos. Ambos geram descrições do mundo verdadeiras, sendo que a ficção se mostra até mais interessante, por seu estímulo à imaginação. Contudo, a divulgação científica realizada por meio da leitura é uma estratégia viável, sendo vitais 
esforços para aproximá-la do grande público, uma vez que uma leitura de qualidade representa a oportunidade de ampliar a visão do mundo. Com o hábito da leitura, o homem pode tomar consciência das suas necessidades, promovendo assim a sua transformação e a do mundo (DUTRA, 2011).

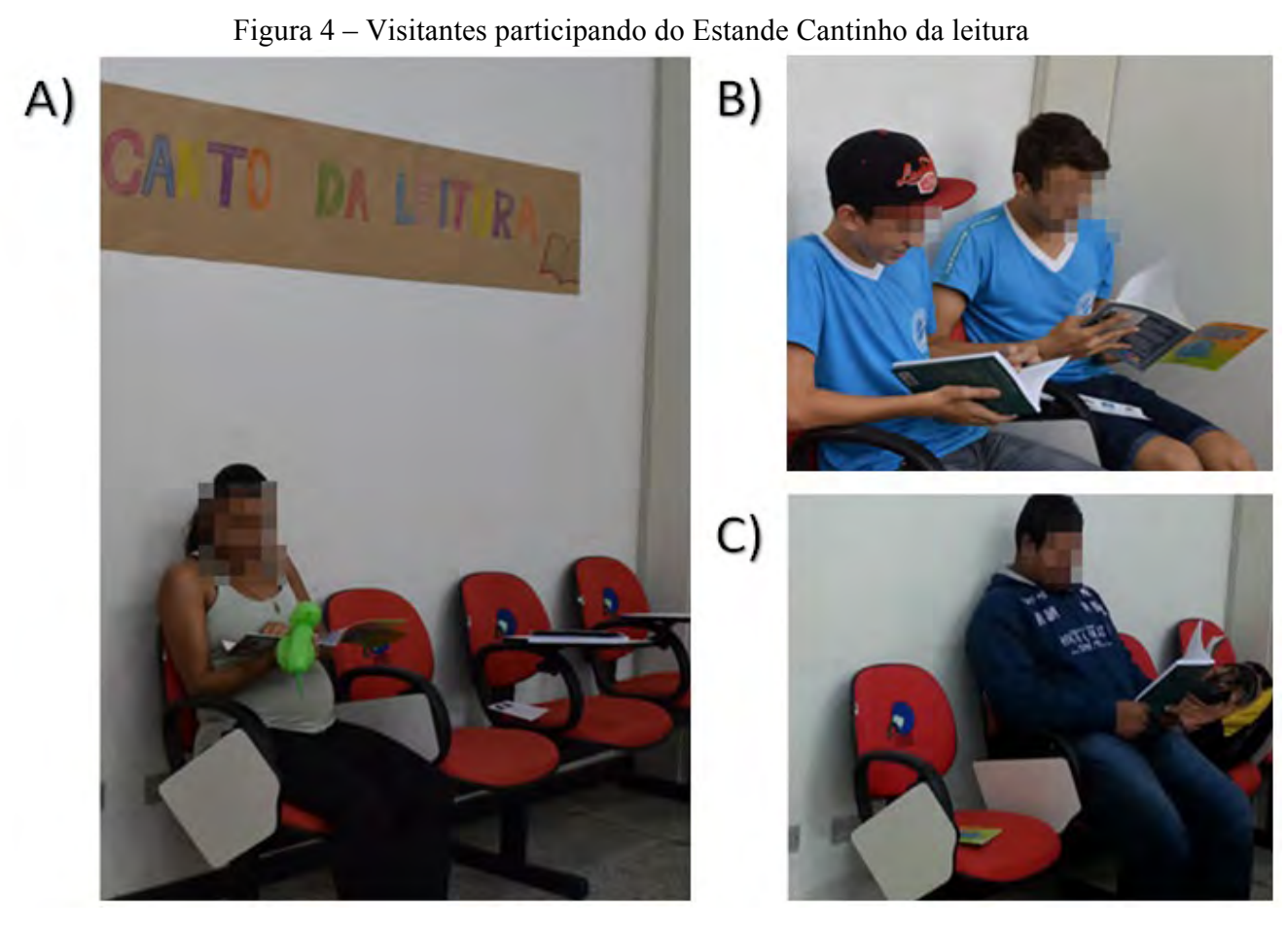

Fonte: Fotografia por Bruno Miguel Nogueira de Souza

Com relação ao estande de neurônios de massinha, que surgiu na segunda edição do evento, houve algumas divergências entre o planejamento e a execução. A princípio seria usado biscuit na modelagem dessa atividade, como mostra a imagem "B" da Figura 5. Porém, por ter secagem rápida ela não foi utilizada, pois exige um pouco mais de experiência e/ou coordenação para fazer o formato proposto antes que o mesmo seque. Além disso, nesse estande tivemos apenas um monitor que atendia até três crianças simultaneamente. Caso tivéssemos mais monitores disponíveis, provavelmente a massa de biscuit poderia ser utilizada. Assim, optou-se pelo uso de massa de modelar à base de amido, que é mais maleável. Devido ao fato dela ter uma textura amolecida, a mesma grudava muito na mesa, então foi utilizada uma base de papel como mostram as imagens " $A$ " e " $C$ " da Figura 5. Por ser uma prática artística tridimensional, modelar por meio de massinhas possibilita que as 
crianças melhorem suas habilidades motoras e trabalhem sua criatividade (SILVA et al., 2013).

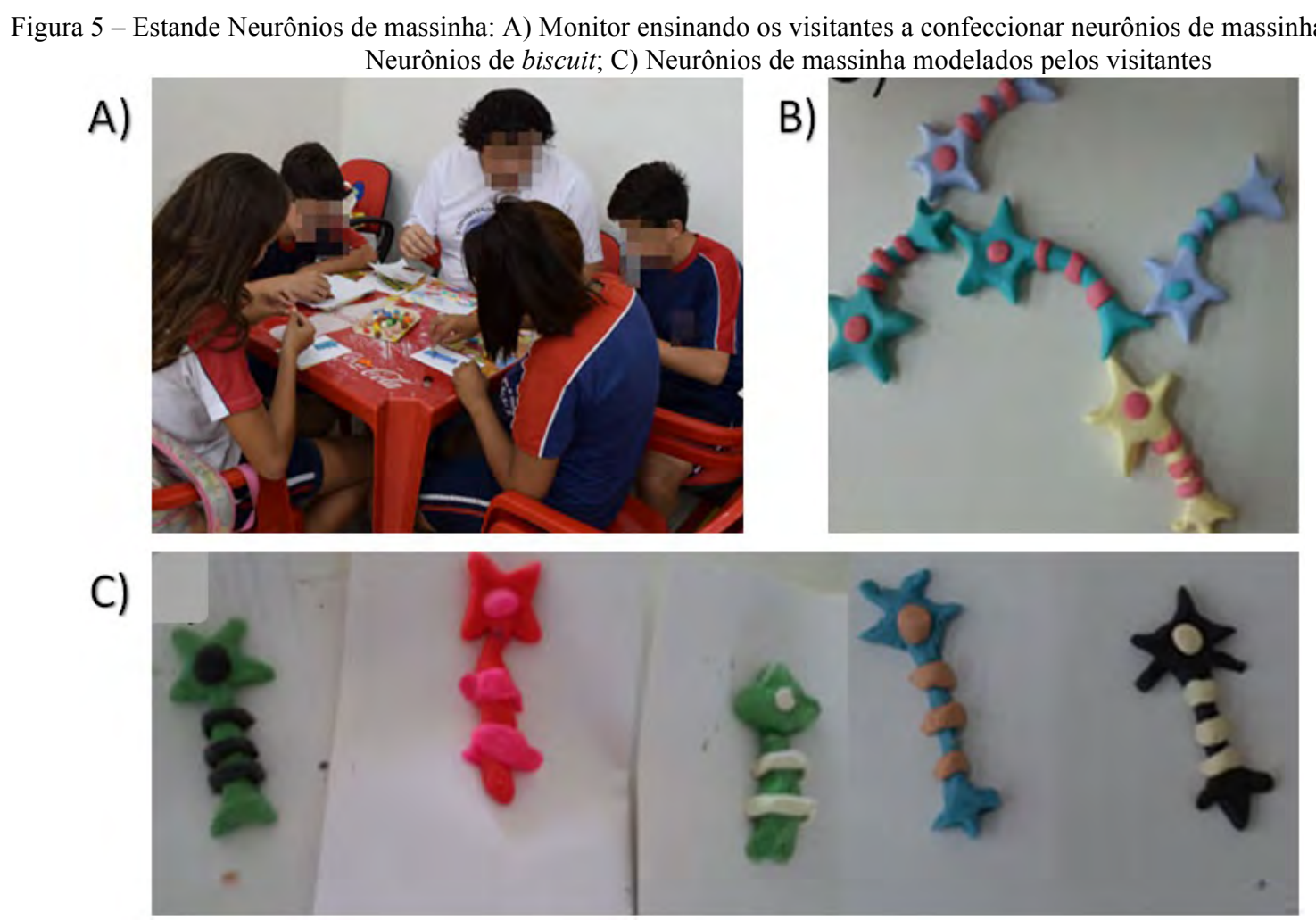

Fonte: Fotografia por Bruno Miguel Nogueira de Souza

Outro novo estande que surgiu em 2015 foi sobre o sono. Segundo Tarouco et al. (2004), jogos ao estilo de caça-palavras e palavras cruzadas podem ser muito eficientes em facilitar o aprendizado, já que são divertidos e motivadores. Além disso, exercitam as funções mentais e intelectuais do jogador aumentando a capacidade de entendimento e retenção sobre o conteúdo proposto. Nessa imagem é possível ver os participantes engajados na atividade de pintura e caça-palavras com palavras-chaves que eles ouviam na explicação da monitora (Figura 6). Nesse estande, apenas uma monitora ficou responsável por essa atividade. De acordo com a monitora, muitos alunos só faziam a atividade de caça-palavra e passavam para outro estande. 


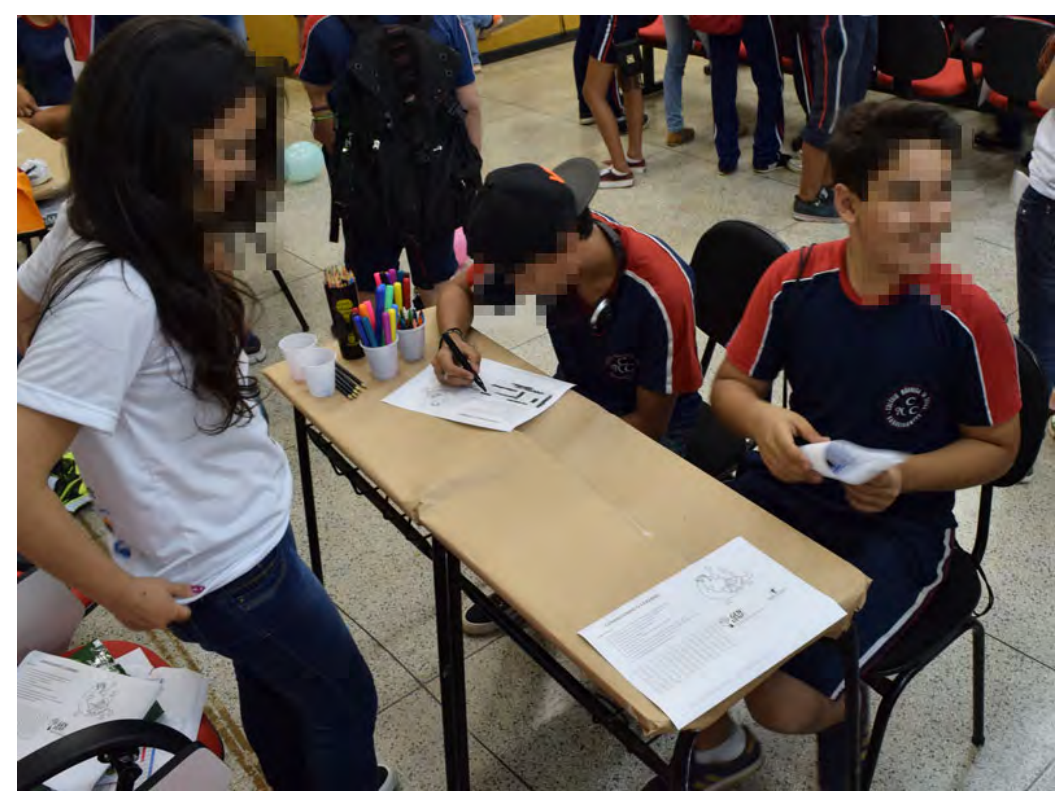

Fonte: Fotografia por Bruno Miguel Nogueira de Souza

O estande de prevenção de drogas teve como objetivo mostrar às crianças e aos jovens as diferentes áreas cerebrais que são ativadas com o uso dos diversos tipos de drogas, apontando que cada droga tem uma ação a nível cerebral. Os monitores relataram que, no geral, os jovens não demonstraram interesse nas atividades de pintura, fato diferente das crianças, que se mostraram entusiasmadas em pintar corretamente cada área cerebral afetada no uso de cada tipo de droga específica.

As atividades de desenho e pintura fazem parte do desenvolvimento emocional das crianças, deixando-as mais alegres, com melhora do autoconhecimento e da autoestima. Por meio das práticas artísticas é possível alcançar um melhor resultado no aprendizado das crianças, pois pode ocorrer um despertar de emoções que melhoram a compreensão (MEDEIROS, 2010; VALLADARES; CARVALHO, 2006). Os monitores relataram ainda que algumas crianças solicitaram três folhas para pintar, especificamente uma folha para cada área diferente que é ativada no uso de cada um dos três tipos de drogas apresentadas. Esse fato pode demonstrar que a pintura estimula a concentração e a atenção dos indivíduos, neste caso, das crianças (VALLADARES; CARVALHO, 2006).

Para os adolescentes, a utilização dos óculos simuladores de embriaguez (3B scientific $\left.{ }^{\circledR}\right)$ foi mais interessante, pois puderam ver/sentir os efeitos do álcool de forma 
sóbria, já que os mesmos promovem distorção visual, alteração da sensação de profundidade e percepção da distância, tendo como consequência a falta de coordenação. Durante a utilização dos óculos, os visitantes sentiam que sua coordenação motora estava alterada, não conseguiam andar em linha reta, ou andavam com muita dificuldade, bem como tiveram dificuldade para desviar dos obstáculos (Figura 7). Os monitores descreveram essa experiência prática como uma atividade prazerosa. Os adolescentes se encontram em uma fase de curiosidade e experimentação de tudo que é novo (CAVALCANTE; ALVES; BARROSO, 2008), o que pode fazer com que sejam seduzidos pelo uso do álcool. Por meio dessas atividades, eles puderam experimentar, sem estarem de fato sob efeito do álcool, alguns sintomas sensoriais que o mesmo causa na percepção do indivíduo. Desse modo, eles puderam perceber que não são capazes de controlar de forma precisa seus movimentos, o que foi correlacionado com o perigo de beber e dirigir.

Figura 7 - Atividades no estande de prevenção de drogas: A) e D) atividade de pintura de áreas cerebrais; B) e C) atividade com o uso dos óculos
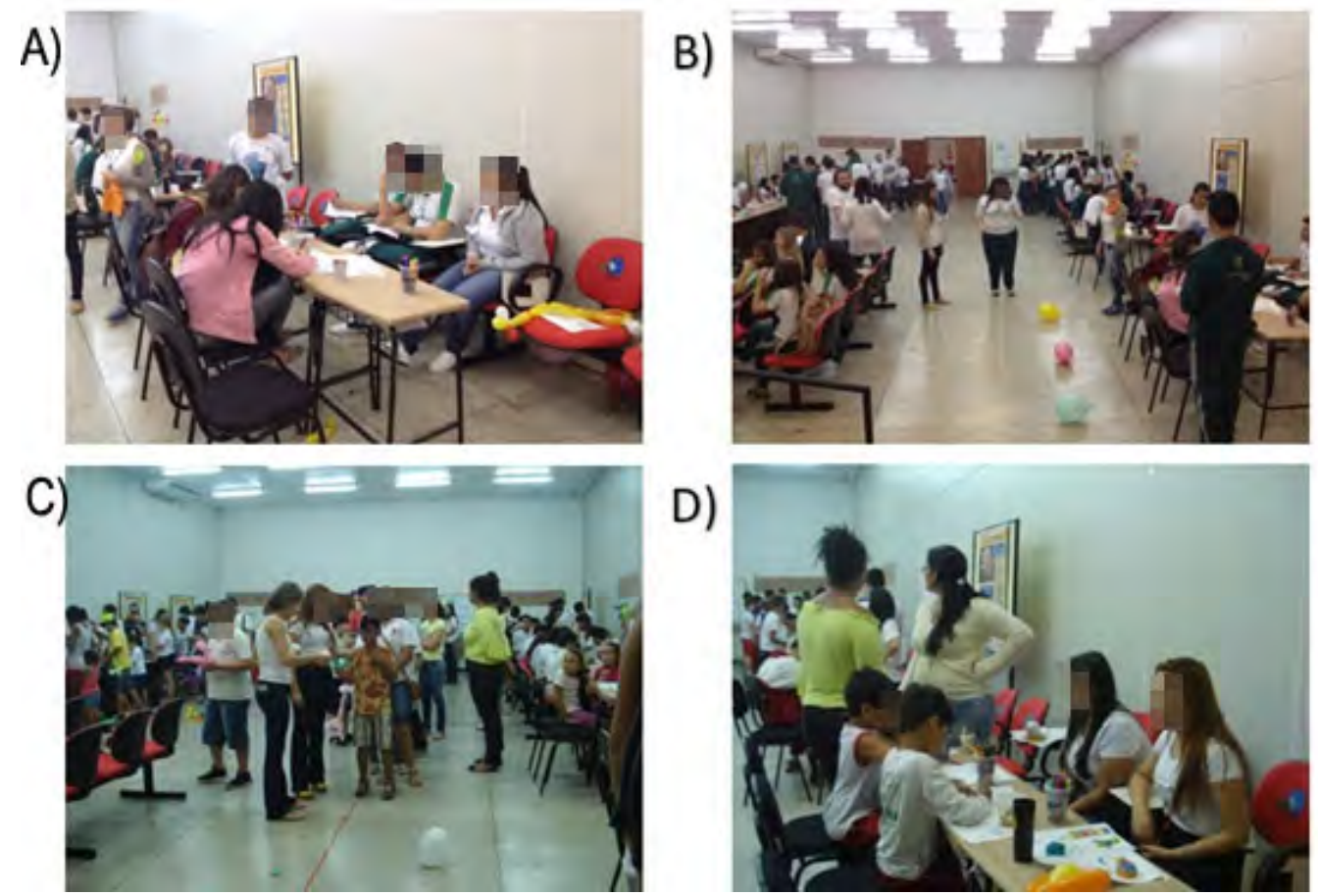

D)

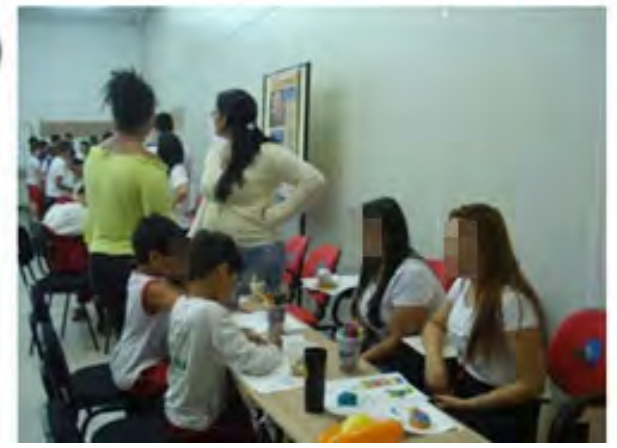

Fonte: Fotografia por Ana Lucia De Grandi 
No estande “Aprendizado e Lousa Digital”, cujo foco era uma atividade lúdica envolvendo a produção de desenhos, acredita-se que os visitantes deram forma e sentido ao conteúdo que foi assimilado anteriormente nos outros estandes (Figura 8). A experiência artística, além de despertar o interesse e curiosidade, permite também aguçar a percepção dos visitantes desafiando seus conhecimentos prévios.

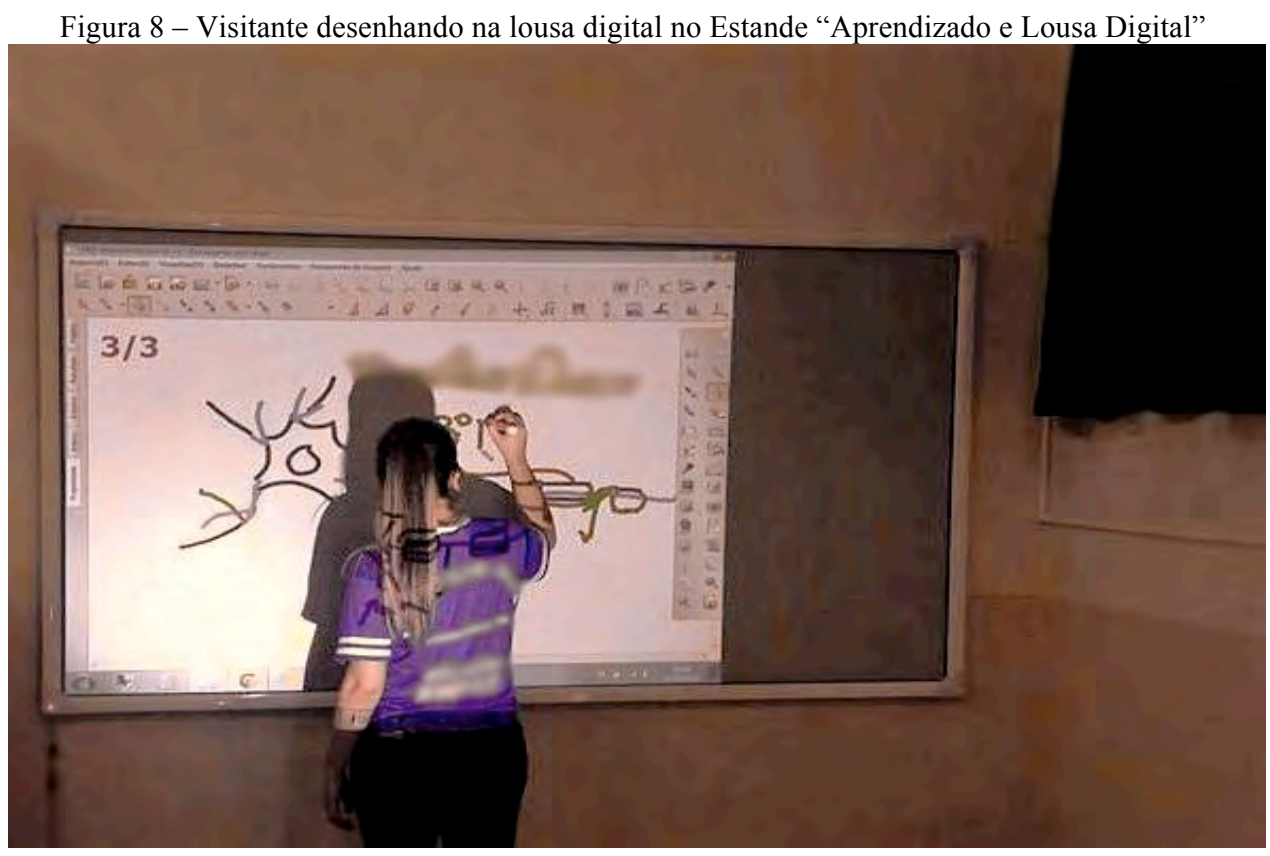

Fonte: Fotografia por Bruna Jamila de Castro

Como destaca Hanauer (2011), o desenho é um ato inteligente de representação, um ato essencial do processo de desenvolvimento da criança. Ao desenhar, desenvolve-se a autonomia, criatividade e criticidade, ampliando as potencialidades de expressão. Ainda segundo o autor, o desenho propicia ao sujeito estabelecer relações do seu mundo interior com o exterior, e assim adquirir e reformular seus conceitos e aprimorar suas capacidades. Isto pode ser observado nos desenhos realizados pelas crianças e adolescentes que passaram pelo estande: apesar de todos os desenhos versarem acerca da estrutura de um neurônio, que já havia sido apresentada em outros estandes, foram observados diferentes desenhos, marcados de individualidade, que reforçam a ideia de que há uma interação e reformulação dos conhecimentos prévios ao desenhar. Notou-se ainda que a interatividade proporcionada pela 
lousa digital influenciou diretamente no interesse/motivação do visitante do estande, proporcionando momentos prazerosos e divertidos.

\section{CONSIDERAÇÕES FINAIS}

De um ponto de vista panorâmico notamos que as práticas artísticas, tais como pintura, desenho, escultura, podem ser utilizadas como estratégia pedagógica e ferramenta para auxiliar pessoas não pertencentes à comunidade científica a aprenderem outro campo de conhecimento, neste caso em específico, a Neurociência. Como foi possível observar neste relato de experiência, as atividades promoveram a apresentação, a discussão e o pensamento crítico acerca de diversos conhecimentos neurocientíficos, da estrutura e funcionamento do sistema nervoso à relação destas estruturas com comportamentos, visão, memória, ilusões, doenças, bem como também o reconhecimento dos neuromitos.

Pode-se argumentar, neste sentido, que o evento "Conhecendo o cérebro" ao aliar as práticas artísticas com o processo de divulgação da ciência não apenas inovou, mas também favoreceu para romper com a lógica da simples transmissão de conhecimento - comum de eventos desta esfera -, pois além de informar, o evento permitiu ao visitante a interação, que pressupõe uma participação ativa, despertando o interesse e curiosidade para com a neurociência, potência necessária para o aprendizado efetivo. Considerando o argumento de Campos, Bortoloto e Felício (2003), de que a aprendizagem significativa de conhecimentos torna-se mais fácil quando é apresentada em forma de atividade lúdica/recreativa, pode-se inferir que a união "prática artística-educação-conhecimento científico" mostrou-se uma alternativa viável, que pode vir a preencher lacunas deixadas pelo processo tradicional da divulgação científica.

Acreditamos, como Braga, Madalosso e Schlichta (2015), que a Arte pode mediar à aprendizagem, inclusive em espaços culturais e expositivos. E que a valorização da criatividade e da inovação através de ações diferenciadas de divulgação científica, pode criar um clima mais favorável de aprendizagem e revitalizar o interesse da comunidade nãocientífica pela ciência, assim como ressalta Valadares (2001). 


\section{REFERÊNCIAS}

ALBAGLI, S. Divulgação científica: informação científica para a cidadania. Ciência da informação, v. 25, n. 3, p. 396-404, 1996.

ALENCAR, E. M. L. S.; FLEITH, D. S. Contribuições teóricas recentes ao estudo da criatividade. Psicologia: Teoria e Pesquisa, v.19, n. 1, p. 1-8, 2003.

BRAGA, J. C.; MADALOSSO, J.D.; SCHLICHTA, C. Mediação de artes para espaços escolares e museológicos como forma de inclusão. Revista Educação, Artes e Inclusão, v. 11, n. 1, p. 10-27, 2015.

CAMPOS, C. R. P. (Org.) Divulgação científica e ensino de ciências: debates preliminares. Vitória: IFES, 2015.

CAMPOS, L. M. L.; BORTOLOTO, T. M.; FELÍCIO, A. K. C. A produção de jogos didáticos para o ensino de ciências e biologia: uma proposta para favorecer a aprendizagem. Caderno dos núcleos de Ensino, v. 47, p.47-60, 2003.

CAVAlCANTE, M. B. P. T.; ALVES, M.D.S.; BARROSO, M. G. T. Adolescência, álcool e drogas: uma revisão na perspectiva da promoção da saúde. Escola Anna Nery Revista de Enfermagem, v. 12 , n. 3, p. 555-559, 2008.

COSTA, D. R.; SOUZA, D. C.; NASCIMENTO JÚNIOR, A. F. A Confecção de artesanato com material reciclado como uma contribuição para a educação ambiental. In: FÓRUM NACIONAL DO MEIO AMBIENTE, 3., 2005, Anais... Santa Rosa: Unijuí, 2005. p. 280-287.

DERDYK, E. Formas de pensar o desenho: desenvolvimento do grafismo infantil. Scipione, 1989.

DUTRA, V. L. R. Abordagem funcional da gramática na Escola Básica. In: CONGRESSO INTERNACIONAL DA ABRALIN. Anais... Curitiba, 2011. Disponível em:<www.abralin.org>. Acesso em: 19 ago. 2017.

EÇA, T. T. P. Educação através da arte para um futuro sustentável. Caderno Cedes, v. 30, n. 80, p. $13-25,2010$.

EISNER, E. The arts and the creation of mind. New Haven: Yale University Press, 2002.

EKUNI, R.; POMPEIA, S. O impacto da divulgação científica na perpetuação de neuromitos na educação. Revista da Biologia, v. 15, n. 1, p. 1-8, 2016.

EKUNI, R.; SOUZA, B. M. N.; COSTA, C. L.; OTOMURA, F. H. Projeto de Extensão Grupo de Estudos em Neurociência: divulgando neurociência e despertando vocações. Revista Brasileira de Extensão Universitária, v. 5, p. 55-59, 2014.

EKUNI, R.; SOUZA, B. M. N.; WATANABE, A. K.; SANTOS, C. H. C.; MACHADO, G. A.; SOUZA-JUNIOR, E. J.; CALVO, J. V. C.; GAIOTTE, L. B.; SILVA, M.A.; EBARA, M. M.; VIEIRA, M. N. F.; CESARIO, R. C. Evento 'Conhecendo o cérebro': divulgando e despertando interesse na neurociência. Revista Ciência em Extensão, v.12, n.2, p.125-140, 2016.

EKUNI, R.; ZEGGIO, L.; BUENO, O.F.A. Caçadores de Neuromitos: o que você sabe sobre seu cérebro é verdade? São Paulo: Editora Memnon, 2015. 
FAVARETTO, C. F. Arte contemporânea e educação. Revista Iberoamericana de Educación. n. 53, p. 225-235, 2010.

FLEITH, D. S.; ALENCAR, E. M. L. S. Autoconceito e Clima Criativo. Psico-USF, Bragança Paulista, v. 17, n. 2, p. 195-203, 2012.

GIRARDELLO, G. Imaginação: arte e ciência na infância. Pro-Posições, Campinas, v. 22, n. 2, p. 75 92, 2011.

GOMES, K. B.; NOGUEIRA, S. M. A. Ensino da Arte na escola pública e aspectos da política educacional: contexto e perspectivas. Ensaio: Avaliação e Políticas Públicas em Educação, v. 16, n. 61, p.583-596, 2008.

HANAUER, F. Riscos e Rabiscos-O Desenho na Educação Infantil. Revista de Educação do IDEAU - Instituto de Desenvolvimento Educacional do Alto Uruguai, v. 6, n. 13, p.73-82, 2011.

HOLDEFER, A. M.; VIVIAN, D. A; CUNHA, F.; REBOLO, L. L.; NASCIMENTO JÚNIOR, A.F. Utilizando cartoplex e bordado como forma alternativa para o ensino de Etologia. In: ENCONTRO ANUAL DE ETOLOGIA, 20., Anais... Natal: UFRN, 2002. p. 349.

HOWARD-JONES, P. A. Neuroscience and education: myths and messages. Nature Reviews Neuroscience, v. 15, n. 12, p. 817-824, 2014.

LIBERA, L. D.; ANSOLIN, T. L.; BARCARO, C. ; CALISTO, A. P. L.; TEIXEIRA, V. L.; NASCIMENTO JÚNIOR, A. F. A utilização de papel maché, dobradura e bordado como material pedagógico no ensino de educação ambiental. In: ENCONTRO PARANAENSE DE EDUCAÇÃO AMBIENTAL, 6., 2003, Anais... Campo Mourão: UNESPAR, 2003. p.1-4.

MEDEIROS, S.E.O.P. Arteterapia de crianças e psicoterapia infantil (ludoterapia), semelhanças e divergências. 2010. 42 f. Monografia (Especialização Lato Sensu em Arteterapia). São Paulo. Master School/Universidade São Marcos, São Paulo, 2010.

MUSEU Itinerante de Neurociências. Neurobalão. Disponível em: $<$ http://www.cienciasecognicao.org/min/?page_id=1691>. Acesso em: 30 out. 2014.

NASCIMENTO JÚNIOR, A. F.; SOUZA, D. C. O fazer artístico na popularização do conhecimento biológico: relato de experiências. Revista Eletrônica do Mestrado em Educação Ambiental, v. 23, p. 71-87, 2009.

O'CONNOR, C.; REES, G.; JOFFE, H. Neuroscience in the public sphere. Neuron, v. 74, n. 2, p. 220-226, 2012.

PASQUINELLI, Elena. Neuromyths: Why do they exist and persist?. Mind, Brain, and Education, v. 6, n. 2, p. 89-96, 2012.

PIMENTEL, L. G. Cognição imaginativa. Revista do Programa de Pós-graduação em Artes da EBA/UFMG, v. 3, n. 6, p. 96-104, 2013.

RAMALDES, K. Ensino da arte - qual ensino queremos? Revista Educação, Artes e Inclusão, v. 13, n. 2, 2017. 
RETRATOS da leitura no Brasil. 2015. Disponível em: $<$ http://prolivro.org.br/home/images/2016/Pesquisa_Retratos_da_Leitura_no_Brasil_-_2015.pdf $>$. Acesso em: 28 ago. 2016.

RIBEIRO, P. M.; FERNANDES, H. L. O uso da arte como meio de superar a fragmentação do ensino de ciências: integrando o corpo-organismo ao meio ambiente. In: SIMPÓSIO NACIONAL DE ENSINO DE CIÊNCIA E TECNOLOGIA, 2., 2010. Anais... Ponta grossa: UTFPR, 2010.

ROSENTHAL, M. D. ; GONÇALVES, E. A. Práticas artísticas contemporâneas para crianças. In: SEMINÁRIO NACIONAL DE ARTE E EDUCAÇÃO, 23., 2012, Anais... Montenegro: FUNDARTE, 2012. p. 345-348.

SEABRA, R. D.; SANTOS, E.T. Utilização de técnicas de realidade virtual no projeto de uma ferramenta 3D para desenvolvimento da habilidade de visualização espacial. Revista Educação Gráfica, Bauru, n.9, p.111-122, 2005.

SELBY, E. C.; SHAW, E. J.; HOUTZ, J. C. The creative personality. Gifted Child Quarterly, v. 49, n. 4, p. 300-314, 2005.

SHOLL-FRANCO, A.; VEQUE, T. Fazendo arte com o cérebro. Rio de Janeiro: Ciências e Cognição, 2013.

SILVA, E. A.; OLIVEIRA, F. R.; SCARABELLI, L.; COSTA, M. L. de O.; OLIVEIRA, S. B. Fazendo arte para aprender: A importância das artes visuais no ato educativo. Pedagogia em Ação, v. 2, n. 2, p. 95-104, 2013.

SILVA, R. A.; GUIMARÃES, M. M.. Arte educação: facilitando o ensino de morfologia. Educere: Revista da Educação da UNIPAR. Umuarama. v. 4, n.1, p. 55-63, 2004.

SILVA, S.G.; BROCKINGTON, G.; QUEIROZ, N. As dúvidas de Stem, uma pequena célula multipotente. [S.1.: s.n.], 2003.

SOUZA, D. C.; ARANTES, M. A. P.; NASCIMENTO JUNIOR, A. F. Aproveitamento de jornal para a produção de material didático-pedagógico para o ensino de ecologia e educação ambiental. In: FÓRUM NACIONAL DE EDUCAÇÃO, 3., 2006, Anais..., Torres: ULBRA, 2006. p. 1-12.

TAROUCO, L. M. R.; ROLAND, L. C.; FABRE, M. C. J. M.; KONRATH, M. L. P. Jogos educacionais. Revista Novas Tecnologias na Educação, v. 2, n. 1, 2004.

TEIXEIRA, V. L.; GOELZER, L. P.; NASCIMENTO JÚNIOR, A. F.. Técnica de dobradura como procedimento complementar ao ensino da educação ambiental. In: SEMINÁRIO INTERNACIONAL DE EDUCAÇÃO, 2001, Anais... Cianorte: UEM, 2001. p. 2759-2762.

TEIXEIRA, V. L.; NASCIMENTO JÚNIOR, A. F.. Oficinas de papel maché, E.V.A (Evenil Venílico acetílico) e bordado como subsídios ao ensino de biologia. In: ENCONTRO NACIONAL DE DIFUSÃO TECNOLÓGICA, 2002, Anais... Medianeira: CEFER, 2002. p. 208-209.

VALADARES, E. C. Novas Estratégias de Divulgação Científica e de Revitalização do Ensino de Ciências em Sala de Aula. Física na Escola, v. 2, n. 2, p.10-13, 2001. 
VALLADARES, A. C.; CARVALHO, A. M. P. O desenho do hospital na visão da arteterapia em internações pediátricas. Enfermería global: Revista electrónica semestral de enfermería, n. 9, p. 2$13,2006$.

ZEGGIO, L.; EKUNI, R.; SILVA, M. A.; BUENO, O. F. A. Neurociênicas e Educação: cuidado com os neuromitos! In: EKUNI, R.; ZEGGIO, L.; BUENO, O. F. A. Caçadores de Neuromitos: o que você sabe sobre seu cérebro é verdade? São Paulo: Editora Memnon. 2015, p.142-152.

Recebido em 29 de agosto de 2016 Aprovado em 24 de agosto de 2017 